\title{
QUALIDADE DA ÁGUA E SUA RELAÇÃO ESPACIAL COM AS FONTES DE CONTAMINAÇÃO ANTRÓPICAS E NATURAIS: BACIA HIDROGRÁFICA DO RIO SÃO DOMINGOS - RJ ${ }^{1}$
}

\author{
JULIANA M. MENEZES ${ }^{2}$, RACHEL B. PRADO ${ }^{3}$, GERSON C. DA SILVA JÚNIOR ${ }^{4}$, \\ KÁTIA L. MANSUR ${ }^{5}$, ELBA DOS S. DE OLIVEIRA ${ }^{6}$
}

RESUMO: O objetivo do trabalho foi avaliar a qualidade das águas da Bacia Hidrográfica do Rio São Domingos (BHRSD), correlacionando-a com as possíveis fontes poluidoras advindas das características naturais e antrópicas da área. Alguns parâmetros físico-químicos foram analisados em 65 pontos (superficiais e subterrâneos) de amostragem. Os resultados foram confrontados com os limites estabelecidos pelas Resoluções CONAMA 357/05 (classe 2), que trata das águas superficiais, e CONAMA 396/08 (consumo humano), que contempla as águas subterrâneas. Foram analisados diversos cátions e ânions, temperatura, alcalinidade, $\mathrm{pH}$, condutividade elétrica (CE), sólidos totais dissolvidos (STD), oxigênio dissolvido (OD), demanda bioquímica de oxigênio (DBO), coliformes termotolerantes e alguns agrotóxicos organoclorados e organofosforados. Os parâmetros que apresentaram inconformidades, com maior frequência, foram: alumínio dissolvido, boro total, ferro dissolvido, manganês total, nitratos, $\mathrm{pH}, \mathrm{OD}, \mathrm{DBO}$ e alguns organoclorados e organofosforados. Embora a área esteja situada em terreno cristalino tropical úmido, o que pode justificar os teores elevados de alumínio, manganês e ferro, os resultados apontam que o comprometimento da qualidade das águas da BHRSD é influenciado pela prática agrícola.

PALAVRAS-CHAVE: qualidade de água superficial e subterrânea, agrotóxicos, poluição difusa e pontual, aquíferos fraturados.

\section{WATER QUALITY AND ITS SPATIAL RELATION WITH SOURCES OF NATURAL AND HUMAN CONTAMINATION: SÃO DOMINGOS RIVER BASIN, RIO DE JANEIRO STATE, BRAZIL}

\begin{abstract}
The purpose of this article is the evaluation of São Domingos River Basin (SDRB) water quality and tentative correlations with natural and anthropic polluting sources. In order to achieve it, physicochemical parameters were analyzed in 65 surface and groundwater sampling points, in accordance to standards established by the Brazilian Environmental Authority, CONAMA 357/05, Class 2, for surface water and CONAMA 396/08, Class human, consumption for groundwater. The analyzed parameters include major cations and anions, temperature, $\mathrm{pH}$, electric conductivity, total dissolved solids (TDS), alkalinity, dissolved oxygen (DO), biochemical oxygen demand (BOD), thermotolerant coliforms, organochlorides and organophosphorus compounds. Parameters with concentrations more frequently in unconformity with regulations are: aluminum, boron, iron, manganese, nitrates, DO, BOD and some organochlorides and organophosphorus compounds. Results show that distribution of contamination is strongly influenced by the human presence, such as rural and urban population and tomato culture. Natural aspects also play a major role, since availability of aluminum, iron, and manganese in near-surface waters in tropical environment depends on input from processes taking place in leaf litter and topsoil.
\end{abstract}

KEYWORDS: surface and groundwater quality, pesticides, nonpoint and point pollution, fractured aquifers.

\footnotetext{
${ }^{1}$ Este trabalho é parte integrante do projeto "Planejamento conservacionista das terras e modelagem preditiva de sistemas aquíferos do cristalino para a recarga hídrica em bacias hidrográficas de relevo acidentado", financiado pelo PRODETAB/Embrapa $n^{\circ}$ 08702/01, finalizado em dezembro de 2005.

${ }^{2}$ Geógrafa, Professora, Universidade do Estado do Rio de Janeiro, Faculdade de Geologia, Departamento de Geologia Aplicada (FGEL/DGAP), Fone: (0XX21) 2334-0530, menezesgeo@yahoo.com.br

${ }^{3}$ Bióloga, Pesquisadora, Embrapa Solos - RJ.

${ }^{4}$ Geólogo, Professor Adjunto, Universidade Federal do Rio de Janeiro, Departamento de Geologia, Laboratório de Hidrogeologia.

${ }^{5}$ Geológa, Departamento de Recursos Minerais do Estado do Rio de Janeiro (DRM/RJ).

${ }^{6}$ Química, Instituto Nacional de Tecnologia (INT), RJ.

Recebido pelo Conselho Editorial em: 9-7-2008
}

Aprovado pelo Conselho Editorial em: 25-10-2009 


\section{INTRODUÇÃO}

Diversos estudos em todo o mundo têm mostrado a preocupação com a identificação e a espacialização das fontes de poluição de origem agrícola, apontando a sua relação com resultados da contaminação dos corpos hídricos, como, por exemplo, ANDRADE et al. (2007) e DONADIO et al. (2005), no Brasil, e ZHOU et al. (2007), STIGTER et al. (2006), RAO (2006), ROMERO et al. (2004) e PAUWELS et al. (2001) em outros países. Nesse contexto, são importantes o mapeamento e a localização das águas superficiais e subterrâneas, a identificação em meio cartográfico da qualidade e da quantidade da água e também dos pontos de vulnerabilidade resultantes da integração água $x$ atividade humana. Tais ações são fundamentais na gestão eficiente dos recursos hídricos (ÁVILA et al., 2007).

A Bacia Hidrográfica do Rio São Domingos (BHRSD), localizada no noroeste do Estado do Rio de Janeiro, tem sofrido com a escassez e a alteração da qualidade natural dos seus recursos hídricos. A insuficiência de água deve estar ocorrendo devido à distribuição irregular das chuvas ao longo do ano, assim como ao pequeno percentual de cobertura vegetal, à erosão dos solos e ao assoreamento dos corpos d'água, como consequência da ocupação não planejada das terras e dos sistemas agrícolas não preservacionistas que têm vigorado até o momento na região (FREITAS et al. 2001).

A água superficial não é mais suficiente para atender à demanda dos produtores rurais, e para o seu aproveitamento, os produtores não se furtam em interferir no fluxo natural dos corpos d'água. Para isso, constroem pequenas barragens ao longo dos córregos e as áreas alagadas incrementam as perdas por evaporação e diminuem o potencial hídrico dos mananciais (PRADO et al., 2005).

A alternativa para as práticas agropecuárias e para o abastecimento doméstico é, então, a água subterrânea, porém o ciclo hidrológico encontra-se alterado, e a recarga dos aquíferos encontra-se também prejudicada (MENEZES et al., 2007). Cerca de 60\% do abastecimento de água se dão por meio de poços (públicos ou particulares) ou nascentes na propriedade (IBGE, 2000).

A degradação da água na região encontra-se bastante relacionada à atividade predominante da região, o cultivo do tomate, que além de requerer grandes volumes de água para a irrigação, utiliza grandes quantidades de fertilizantes e pesticidas, na maioria das vezes aplicados de forma indiscriminada. Além das fontes difusas de poluição, as pontuais também são significativas na BHRSD, visto que não há tratamento prévio do esgoto, tanto da população urbana quanto da rural, e esses dejetos são lançados in natura nos cursos d'água e nas várzeas (PRADO et al., 2005).

O objetivo do presente trabalho foi avaliar a qualidade das águas da Bacia Hidrográfica do Rio São Domingos (BHRSD), correlacionando com as possíveis fontes poluidoras advindas das características naturais e antrópicas da área.

\section{MATERIAL E MÉTODOS}

ABHRSD possui aproximadamente $280 \mathrm{~km}^{2}$, sendo $90 \%$ do seu território compreendido pelo município de São José de Ubá e 10\% pelo município de Itaperuna (Figura 1). O Rio São Domingos é afluente do Rio Muriaé, fazendo parte do Complexo Hidrográfico do Rio Paraíba do Sul.

O clima da Região Noroeste Fluminense, baseado na classificação de Köeppen, é o Aw, tropical quente e úmido com estações seca (inverno) e chuvosa (verão) bem marcadas. Em relação aos tipos de solos, nas baixadas (várzeas), localizam-se os Gleissolos, e nas posições ligeiramente mais elevadas, os Planossolos e Cambissolos. Nas áreas de morros e montanhas, estão os Argissolos Vermelhos e Vermelho-Amarelos, que gradativamente dão lugar a Cambissolos e a Neossolos Litólicos, à medida que o relevo fica mais acentuado (LUMBRERAS et al., 2006). 


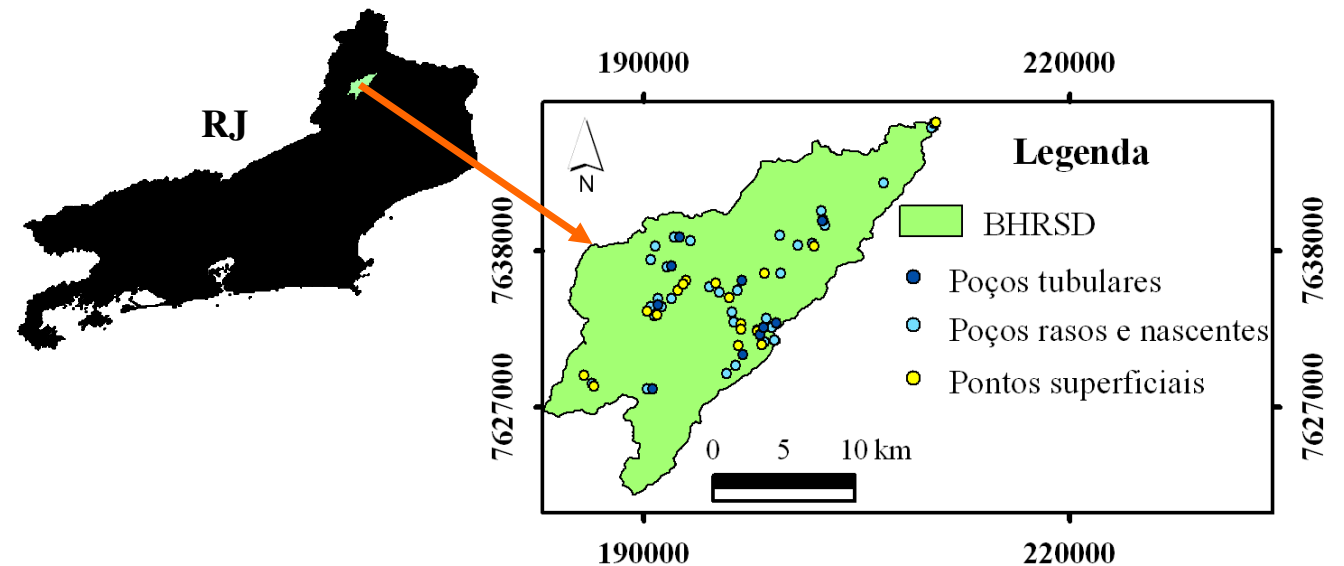

FIGURA 1. Localização da área de estudo e dos pontos amostrais. Location of study area and of the sampling points.

Do ponto de vista geológico, ocorrem dois grandes Domínios, o Juiz de Fora e o Cambuci. No Domínio Juiz de Fora, predominam rochas ortoderivadas granulíticas; no Domínio Cambuci, sobressai um leucocharnockito e estão presentes, subordinadamente, anfibolitos, mármores e gnaisse migmatítico. De forma geral, a mineralogia básica encontrada na BHRSD é composta por plagioclásio, quartzo, ortoclásio, hiperstênio, hornblenda e biotita. Ocorrem, também, granada e microclina. Raras lentes de calcissilicáticas podem aparecer (MANSUR et al., 2006).

Dois tipos de aquíferos foram identificados por FERREIRA et al. (2006), em uma sub-bacia da área de estudo (Barro Branco): o sedimentar (espessuras de 2 a 12) e o fissural (profundidade superior a 30). Os tipos hidroquímicos predominantes na BHRSD são, respectivamente, o bicarbonatado-sódico e o bicarbonatado-misto para as águas dos poços escavados e tubulares. Para esse último tipo de captação, as águas bicarbonatadas-cálcicas também são importantes (MENEZES et al., 2007).

A coleta de água ocorreu em outubro de 2004 e contemplou 37 pontos de águas de circulação rasa (nascentes e poços escavados), 10 poços tubulares e 18 pontos superficiais, o que permitiu a obtenção in situ de valores de temperatura, $\mathrm{pH}, \mathrm{CE}$ e alcalinidade total (método volumétrico com ampolas Titrets ${ }^{\circledR}$ da Chemetrics). Em laboratório, conforme exposto na Tabela 1, foram analisados cátions, ânions, materiais sólidos na água, coliformes termotolerantes, DBO, OD, organoclorados e organofosforados. Todas as análises seguiram metodologia da APHA (1998).

Os parâmetros coliformes termotolerantes, DBO, OD, organoclorados e organofosforados foram analisados em um número menor de pontos por conta da logística necessária no momento da coleta e dos custos das análises.

Os resultados dos parâmetros analisados nas águas subterrâneas foram confrontados com os limites estabelecidos pela Resolução CONAMA 396/08 (BRASIL, 2008) que dispõe sobre a classificação e o enquadramento das águas subterrâneas. Os valores máximos permitidos (VMP) utilizados foram os fixados para o consumo humano, que é um dos principais usos dos recursos hídricos subterrâneos na BHRSD.

Os resultados dos parâmetros analisados nas águas superficiais foram confrontados com os limites estabelecidos pela Resolução CONAMA 357/05 (classe 2) (BRASIL, 2005) que trata das águas superficiais que podem ser destinadas ao abastecimento para consumo humano, após tratamento convencional, à irrigação de hortaliças e plantas frutíferas, entre outros fins. 
TABELA 1. Parâmetros analisados, laboratórios e número de pontos coletados na BHRSD. Analyzed parameters, laboratories and number of points collected in BHRSD.

\begin{tabular}{|c|c|c|}
\hline Parâmetros & Laboratórios & Número de Pontos \\
\hline $\begin{array}{l}\text { Cátions } \\
\mathrm{Al}, \mathrm{As}, \mathrm{B}, \mathrm{Ba}, \mathrm{Be}, \mathrm{Bi}, \mathrm{Ca}, \mathrm{Cd}, \mathrm{Co} \text {, } \\
\mathrm{Cu}, \mathrm{Fe}, \mathrm{K}, \mathrm{Li}, \mathrm{V}, \mathrm{Mo}, \mathrm{Pb}, \mathrm{Se}, \mathrm{Sb}, \mathrm{Si} \text {, } \\
\text { Sr, Ba e Ni }\end{array}$ & Embrapa Solos & $\begin{array}{l}37 \text { pontos de águas de circulação rasa } \\
\text { (nascentes e poços escavados), dez } \\
\text { poços profundos e } 18 \text { pontos } \\
\text { superficiais }\end{array}$ \\
\hline $\begin{array}{l}\text { Ânions } \\
\text { Sulfatos, fosfatos, cloretos, nitritos, } \\
\text { nitratos, fluoretos e brometos }\end{array}$ & Embrapa Solos & $\begin{array}{l}37 \text { pontos de águas de circulação rasa } \\
\text { (nascentes e poços escavados), dez } \\
\text { poços profundos e } 18 \text { pontos } \\
\text { superficiais }\end{array}$ \\
\hline $\begin{array}{l}\text { Sólidos em suspensão, sólidos totais } \\
\text { dissolvidos e sólidos totais }\end{array}$ & $\begin{array}{l}\text { Laboratório de } \\
\text { Hidrogeologia da } \\
\text { UFRJ }\end{array}$ & $\begin{array}{l}34 \text { pontos de águas de circulação rasa } \\
\text { (nascentes e poços escavados), dez } \\
\text { poços profundos e } 18 \text { pontos } \\
\text { superficiais }\end{array}$ \\
\hline $\begin{array}{l}\text { Coliformes termotolerantes, OD e } \\
\text { DBO }\end{array}$ & FEEMA - Campos & $\begin{array}{l}31 \text { pontos de águas de circulação rasa } \\
\text { (nascentes e poços escavados), oito } \\
\text { poços profundos e } 17 \text { pontos } \\
\text { superficiais }\end{array}$ \\
\hline Organoclorados e organofosforados & INT & $\begin{array}{l}\text { Três poços escavados; quatro de poços } \\
\text { profundos e cinco pontos superficiais }\end{array}$ \\
\hline
\end{tabular}

A Resolução CONAMA 396/08 não contém VMP para pH, OD e DBO, por isso os valores de referência utilizados para a avaliação desses parâmetros nas águas subterrâneas foram os contidos na Resolução CONAMA 357/05 (classe 2).

Em seguida, foi efetuada a espacialização dos parâmetros em inconformidade com as Resoluções, considerando os aspectos geológicos e antrópicos, principalmente a localização das culturas de inverno (tomate, pimentão, pepino e abobrinha) da BHRSD mapeadas por ABREU \& FIDALGO (2006).

A espacialização foi realizada no software ArcGis® (versão 8.3 da ESRI), e com o intuito de obter melhor precisão dos resultados, foi utilizada a extensão Spatial Analyst para as interpolações com os resultados dos parâmetros que se apresentaram em desacordo com as normas. O método de interpolação utilizado, o Inverse Distance Weighted (IDW), baseia-se na dependência espacial, ou seja, parte do princípio de que quanto maior for a distância de um ponto em relação ao outro, menor deverá ser a correlação entre seus valores.

\section{RESULTADOS E DISCUSSÃO}

Quanto à qualidade da água analisada na BHRSD, 16 dos 38 parâmetros mensurados apresentaram-se em inconformidade com as legislações de referência, ao menos em uma amostra. Optou-se, por esse motivo, por apresentar somente os resultados desses 16 parâmetros. Na Tabela 2, são apresentados os resultados das análises, e na Tabela 3, o número e o percentual de pontos de água, com parâmetros em desacordo com as resoluções CONAMA 357/05 e 396/08.

Porém, somente foram selecionados para serem analisados quanto a sua distribuição espacial, considerando as características geológicas, hidrogeológicas e de uso do solo, os parâmetros que apresentaram valores que não atenderam aos limites de referência com maior frequência na BHRSD, independentemente do tipo de captação, sendo eles: alumínio dissolvido, boro total, ferro dissolvido, manganês total, nitrato, $\mathrm{pH}, \mathrm{OD}, \mathrm{DBO}$, coliformes termotolerantes e alguns agrotóxicos organoclorados e organofosforados, sendo essas duas últimas categorias de compostos analisadas separadamente na Tabela 4. 
TABELA 2. Resultados dos parâmetros analisados. Results of the analyzed parameters.

\begin{tabular}{|c|c|c|c|c|c|c|c|c|c|c|c|c|c|c|c|c|}
\hline \multicolumn{17}{|c|}{ Parâmetros } \\
\hline & $\mathrm{Al}$ & As & $\mathrm{Ba}$ & B & $\mathrm{Fe}$ & Fluoreto & $\mathrm{Mn}$ & Nitr & Nitrato & $\mathrm{Pb}$ & Sulfato & STD & $\mathrm{pH}$ & OD & DBO & $\begin{array}{c}\text { Coliformes } \\
\text { termotolerantes }\end{array}$ \\
\hline \multicolumn{17}{|c|}{ Unidades } \\
\hline ID & $\mathrm{mg} \mathrm{L}^{-1}$ & $\mathrm{mg} \mathrm{L}^{-1}$ & $\mathrm{mg} \mathrm{L}^{-1}$ & $\mathrm{mg} \mathrm{L}^{-1}$ & $\mathrm{mg} \mathrm{L}^{-1}$ & $\mathrm{mg} \mathrm{L}^{-1}$ & $\mathrm{mg} \mathrm{L}^{-1}$ & $\mathrm{mg} \mathrm{L}^{-1}$ & $\mathrm{mg} \mathrm{L}^{-1}$ & $\mathrm{mg} \mathrm{L}^{-1}$ & $\mathrm{mg} \mathrm{L}^{-1}$ & $\mathrm{mg} \mathrm{L}^{-1}$ & & $\mathrm{mg} \mathrm{L}^{-1}$ & $\mathrm{mg} \mathrm{L}^{-1}$ & NMP \\
\hline $2 \mathrm{~N}$ & ND & ND & 0,10 & 0,89 & 0,00 & 0,21 & 0,01 & 0,00 & 2,59 & ND & 6,81 & 153 & 6,55 & --- & --- & --- \\
\hline $7 \mathrm{~N}$ & ND & ND & 0,03 & 0,53 & 0,00 & 0,61 & 0,01 & 0,00 & 3,23 & ND & 4,46 & 167 & 6,73 & 6,00 & 0,80 & 0 \\
\hline $25 \mathrm{~N}$ & 1,19 & ND & 0,04 & 0,94 & 0,34 & 0,18 & 0,01 & 0,00 & 0,95 & ND & 11,90 & 133 & 6,60 & 8,80 & 1,60 & 170 \\
\hline $33 \mathrm{~N}$ & 0,01 & ND & 0,05 & 0,88 & 0,01 & 0,31 & 0,01 & 0,00 & 6,13 & 0,01 & 3,27 & 139 & 5,96 & 6,80 & 4,00 & 23 \\
\hline $34 \mathrm{~N}$ & 0,02 & ND & 0,08 & 0,74 & 0,01 & 0,04 & 0,01 & 0,00 & 10,07 & ND & 0,69 & 109 & 5,34 & --- & --- & --- \\
\hline $35 \mathrm{~N}$ & 4,18 & ND & 0,06 & 2,26 & 1,61 & 0,53 & 0,01 & 0,00 & 1,10 & 0,01 & 12,11 & 218 & 6,12 & 7,00 & 0,60 & 23 \\
\hline $38 \mathrm{~N}$ & ND & ND & 0,05 & 1,16 & 0,01 & 0,79 & 0,02 & 0,00 & 4,78 & ND & 38,48 & 206 & 6,86 & 6,60 & 6,00 & 0 \\
\hline $40 \mathrm{~N}$ & 0,01 & ND & 0,04 & 3,40 & 0,15 & 0,38 & 0,12 & 0,00 & 4,03 & ND & 5,31 & 1.808 & 6,09 & --- & --- & --- \\
\hline $41 \mathrm{~N}$ & 0,21 & ND & 0,02 & 1,22 & 0,11 & 0,40 & 0,01 & 0,00 & 2,60 & ND & 1,89 & 176 & 5,92 & 6,20 & 3,40 & 80 \\
\hline $43 \mathrm{~N}$ & 0,03 & 0,02 & 0,03 & 1,59 & 0,05 & 0,38 & 0,04 & 0,00 & 4,46 & ND & 5,06 & --- & 6,82 & 6,00 & 8,00 & 13 \\
\hline $52 \mathrm{~N}$ & ND & ND & 0,13 & 0,79 & 0,00 & 0,34 & 0,00 & 0,00 & 5,20 & ND & 5,03 & 121 & 6,05 & 7,40 & 0,40 & 4 \\
\hline $8 \mathrm{R}$ & 0,02 & ND & 0,07 & 0,78 & 0,01 & 1,33 & 0,03 & 0,00 & 2,29 & ND & 13,36 & 254 & 6,59 & 2,30 & 1,50 & 80 \\
\hline $11 \mathrm{R}$ & ND & ND & 0,11 & 0,63 & 0,00 & 0,21 & 0,00 & 0,00 & 0,51 & ND & 12,88 & 176 & 6,13 & 4,60 & 4,00 & 110 \\
\hline $12 \mathrm{R}$ & 0,04 & ND & 0,05 & 0,70 & 0,00 & 1,68 & ND & 0,00 & 6,19 & ND & 11,98 & 237 & 6,69 & 5,20 & 3,00 & 50 \\
\hline $13 \mathrm{R}$ & 0,01 & ND & 0,30 & 1,14 & 0,02 & 0,25 & 0,01 & 0,00 & 14,99 & ND & 7,45 & 235 & 5,98 & 2,60 & 2,20 & 13 \\
\hline $14 \mathrm{R}$ & ND & ND & 0,18 & 0,77 & 0,00 & 0,83 & 0,01 & 0,00 & 9,09 & ND & 18,41 & --- & 6,41 & 5,20 & 3,00 & 130 \\
\hline $15 \mathrm{R}$ & ND & ND & 0,05 & 0,84 & 0,00 & 0,50 & 0,10 & 0,00 & 2,79 & ND & 18,55 & --- & 6,39 & 3,20 & 3,00 & 0 \\
\hline $16 \mathrm{R}$ & 0,00 & ND & 0,09 & 0,90 & 0,00 & 0,62 & 0,04 & 0,00 & 12,16 & ND & 45,86 & 358 & 6,28 & 4,40 & 5,00 & 0 \\
\hline $18 \mathrm{R}$ & ND & ND & 0,28 & 1,07 & 0,04 & 0,52 & 0,05 & 0,06 & 13,27 & ND & 11,11 & 208 & 6,30 & 2,00 & 10,50 & 30 \\
\hline 19R & ND & 0,02 & 0,10 & 1,11 & 0,03 & 0,85 & 0,01 & 0,00 & 3,42 & ND & 12,37 & 244 & 6,64 & 2,20 & 1,40 & 110 \\
\hline $20 \mathrm{R}$ & 0,03 & ND & 1,22 & 1,00 & 0,01 & 0,13 & 0,24 & 0,00 & 7,36 & ND & 2,71 & 708 & 5,62 & 3,00 & 2,00 & 80 \\
\hline $21 \mathrm{R}$ & 0,01 & ND & 0,09 & 0,88 & 0,02 & 0,18 & 0,01 & 0,00 & 5,20 & ND & 1,12 & 159 & 6,82 & 6,00 & 5,00 & 300 \\
\hline $23 \mathrm{R}$ & ND & ND & 0,20 & 1,09 & 0,04 & 0,28 & 0,63 & 2,25 & 3,68 & ND & 22,00 & 366 & 7,30 & 7,00 & 3,40 & 30 \\
\hline $24 \mathrm{R}$ & 0,49 & ND & 0,15 & 2,25 & 0,21 & 0,39 & 0,09 & 0,00 & 17,92 & ND & 109,37 & 539 & 6,39 & 3,00 & 3,20 & 23 \\
\hline $25 \mathrm{R}$ & 0,66 & ND & 0,08 & 1,11 & 0,26 & 0,13 & 0,42 & 0,00 & 1,32 & ND & 2,55 & 175 & 5,77 & 1,40 & 4,00 & 900 \\
\hline 26R & ND & ND & 0,10 & 0,92 & 0,01 & 0,34 & 0,51 & 0,00 & 16,05 & ND & 2,88 & 250 & 6,06 & 2,00 & 3,50 & 23 \\
\hline $27 \mathrm{R}$ & 0,13 & ND & 0,20 & 0,81 & 0,27 & 0,29 & 0,01 & 0,00 & 19,87 & ND & 13,93 & 5 & 6,62 & 4,40 & 2,10 & 24 \\
\hline $28 \mathrm{R}$ & 0,01 & ND & 0,04 & 1,21 & 0,01 & 0,58 & 0,00 & 0,00 & 3,00 & ND & 1,80 & 139 & 6,06 & 6,00 & 3,40 & 80 \\
\hline $29 \mathrm{R}$ & 0,02 & ND & 0,16 & 1,13 & 0,06 & 0,31 & 0,03 & 0,00 & 6,10 & 0,02 & 3,31 & 252 & 6,46 & 6,60 & 5,60 & 300 \\
\hline 31R & 0,02 & ND & 0,13 & 0,52 & 0,01 & 0,02 & 0,03 & 0,00 & 1,63 & ND & 2,51 & 3.124 & 5,22 & 3,60 & 11,00 & 13 \\
\hline 36R & ND & ND & 0,17 & 0,95 & 0,00 & 0,92 & 0,06 & 0,00 & 15,72 & 0,02 & 10,44 & 316 & 6,31 & 7,40 & 4,00 & 30 \\
\hline $39 \mathrm{R}$ & ND & ND & 0,01 & 0,93 & 0,01 & 0,80 & 0,01 & 0,00 & 6,63 & ND & 14,60 & 174 & 6,42 & 4,80 & 4,50 & 23 \\
\hline $43 \mathrm{R}$ & 0,01 & ND & 0,05 & 1,11 & 0,00 & 1,28 & 0,02 & 0,00 & 4,68 & ND & 133,77 & 213 & 6,75 & --- & --- & --- \\
\hline 44R & 0,07 & ND & 0,05 & 1,49 & 0,03 & 0,86 & 0,07 & 0,00 & 5,07 & ND & 64,78 & 574 & 6,91 & --- & --- & --- \\
\hline 48R & 0,14 & ND & 0,03 & 1,18 & 0,07 & 0,59 & 0,01 & 0,00 & 4,17 & ND & 3,96 & 204 & 5,95 & --- & --- & --- \\
\hline $52 \mathrm{R}$ & ND & ND & 0,05 & 0,80 & 0,00 & 0,28 & ND & 0,00 & 8,51 & ND & 10,37 & 228 & 6,06 & 1,80 & 2,80 & 0 \\
\hline $53 \mathrm{R}$ & ND & ND & 0,16 & 0,84 & 0,01 & 0,14 & 0,05 & 0,00 & 17,74 & ND & 6,40 & 230 & 5,94 & 1,60 & 3,20 & 8 \\
\hline $2 \mathrm{P}$ & 0,01 & ND & 0,28 & 12,70 & 9,33 & 0,27 & 2,04 & 0,00 & 0,00 & ND & 6,50 & 384 & 7,20 & 5,00 & 4,20 & 23 \\
\hline $4 \mathrm{P}$ & ND & ND & 0,07 & 0,85 & 0,01 & 0,69 & 0,15 & 0,00 & 1,76 & ND & 140,48 & 709 & 7,16 & 2,40 & 1,20 & 8 \\
\hline $6 \mathrm{P}$ & ND & ND & 0,03 & 1,56 & 0,02 & 0,82 & 0,03 & 0,00 & 2,73 & ND & 17,98 & 443 & 6,31 & 3,00 & 3,70 & 300 \\
\hline $7 \mathrm{P}$ & 0,01 & ND & 0,08 & 0,63 & 0,00 & 0,93 & 0,01 & 0,00 & 3,70 & ND & 25,35 & 2.443 & 7,35 & 6,60 & 1,80 & 300 \\
\hline $8 \mathrm{P}$ & 0,00 & ND & 0,03 & 1,52 & 0,56 & 0,88 & 0,10 & 0,00 & 0,97 & ND & 37,23 & 302 & 6,88 & 5,60 & 2,10 & 23 \\
\hline $12 \mathrm{P}$ & ND & 0,03 & 0,06 & 2,48 & 0,03 & 0,49 & 0,40 & 0,00 & 1,04 & ND & 354,49 & 1.038 & 6,99 & 7,20 & 0,60 & 13 \\
\hline $17 \mathrm{P}$ & ND & ND & 0,06 & 0,93 & 0,06 & 0,25 & 0,04 & 0,00 & 0,19 & ND & 12,38 & --- & 6,31 & 7,20 & 0,60 & 0 \\
\hline 19P & ND & ND & 0,06 & 2,96 & 2,18 & 0,43 & 0,21 & 0,00 & 0,00 & ND & 118,18 & --- & 6,60 & 2,60 & 3,70 & 0 \\
\hline $20 \mathrm{P}$ & ND & ND & 0,08 & 0,87 & 0,01 & 0,53 & 0,04 & 0,00 & 1,90 & ND & 22,20 & 382 & 6,51 & 6,80 & 4,50 & 50 \\
\hline $21 \mathrm{P}$ & ND & ND & 0,03 & 1,02 & 0,01 & 1,08 & 0,26 & 0,00 & 8,08 & ND & 79,27 & 497 & 6,43 & 6,20 & 7,20 & 8 \\
\hline $1 \mathrm{~S}$ & 0,03 & ND & 0,11 & 0,82 & 0,29 & 0,23 & 0,06 & 0,00 & 0,00 & ND & 0,92 & 150 & 7,24 & 7,00 & 0,80 & 23 \\
\hline $6 \mathrm{~S}$ & 0,09 & ND & 0,16 & 1,05 & 0,10 & 0,42 & 0,23 & 0,00 & 0,00 & ND & 1,38 & 232 & 7,62 & 3,80 & 11,20 & 130 \\
\hline $7 \mathrm{~S}$ & 0,14 & ND & 0,14 & 1,33 & 0,26 & 0,72 & 0,31 & 0,00 & 0,00 & ND & 0,58 & 236 & 7,69 & 9,00 & 5,40 & 30 \\
\hline $9 \mathrm{~S}$ & ND & ND & 0,08 & 1,26 & 0,13 & 0,47 & 0,10 & 0,00 & 0,00 & ND & 1,66 & --- & 7,64 & --- & --- & --- \\
\hline $12 \mathrm{~S}$ & 0,12 & ND & 0,11 & 1,61 & 0,79 & 0,33 & 0,25 & 0,00 & 0,79 & ND & 5,93 & 3.064 & 7,00 & 5,00 & 22,00 & 80 \\
\hline $17 \mathrm{~S}$ & 0,05 & ND & 0,10 & 1,40 & 0,38 & 0,27 & 0,22 & 0,00 & 2,95 & ND & 2,83 & 243 & 6,97 & 5,20 & 13,00 & 500 \\
\hline $19 \mathrm{~S}$ & 0,09 & ND & 0,12 & 3,33 & 0,77 & 0,24 & 0,14 & 0,00 & 0,38 & ND & 3,31 & 119 & 6,83 & 2,00 & 10,70 & 240 \\
\hline $20 \mathrm{~S}$ & ND & ND & 0,10 & 1,08 & 0,30 & 0,21 & 0,08 & 0,00 & 4,59 & ND & 6,42 & 136 & 5,63 & 3,40 & 9,30 & 8 \\
\hline $21 \mathrm{~S}$ & 0,20 & ND & 0,15 & 2,73 & 0,26 & 0,60 & 1,11 & 0,00 & 0,10 & ND & 1,55 & 246 & 6,89 & 9,80 & 2,60 & 0 \\
\hline $22 \mathrm{~S}$ & 0,01 & ND & 0,10 & 0,94 & 0,53 & 0,27 & 0,18 & 0,00 & 0,05 & ND & 1,08 & 126 & 6,85 & 1,80 & 10,00 & 110 \\
\hline $23 \mathrm{~S}$ & 1,58 & ND & 0,13 & 2,68 & 1,26 & 0,25 & 0,19 & 0,00 & 1,20 & ND & 4,02 & 5.971 & 6,85 & 4,80 & 12,00 & 180 \\
\hline $24 \mathrm{~S}$ & 0,04 & ND & 0,10 & 0,84 & 0,33 & 0,31 & 0,19 & 0,00 & 0,00 & ND & 0,65 & 246 & 7,47 & --- & --- & --- \\
\hline $27 \mathrm{~S}$ & 0,16 & ND & 0,18 & 0,87 & 0,09 & 0,52 & 0,29 & 0,00 & 0,00 & ND & 4,85 & 238 & 7,75 & 7,00 & 6,50 & 170 \\
\hline $29 \mathrm{~S}$ & 0,02 & ND & 0,06 & 0,67 & 0,09 & 0,66 & 0,20 & 0,00 & 0,00 & ND & 12,58 & 311 & 7,71 & 6,40 & 5,00 & 30 \\
\hline $30 \mathrm{~S}$ & 0,06 & ND & 0,21 & 2,00 & 0,42 & 0,38 & 1,64 & 0,00 & 0,05 & ND & 2,20 & 320 & 7,01 & --- & --- & --- \\
\hline $32 \mathrm{~S}$ & 0,53 & ND & 0,30 & 1,49 & 0,32 & 0,07 & 0,20 & 0,00 & 0,07 & 0,02 & 2,22 & 104 & 8,24 & 9,00 & 7,60 & 30 \\
\hline $36 \mathrm{~S}$ & ND & ND & 0,14 & 1,19 & 0,29 & 0,19 & 0,44 & 0,00 & 0,00 & ND & 1,42 & 110 & 7,20 & 6,80 & 2,00 & 13 \\
\hline $37 \mathrm{~S}$ & 2,15 & ND & 0,11 & 7,39 & 1,52 & 0,23 & 0,16 & 0,00 & 0,67 & ND & 5,89 & 248 & 7,04 & 1,40 & 18,00 & 500 \\
\hline
\end{tabular}

ID: identificação da amostra; NMP: número mais provável; - amostra não analisada; ND: não detectado; N: nascentes; R: poços escavados (rasos); P: poços tubulares (profundos); S: pontos superficiais. 
TABELA 3. Número e percentual de pontos de água com parâmetros em inconformidade com as resoluções CONAMA 357/05 e 396/08. Number and percentage of water points exceeding Maximum Contaminant Level (MCL) according to the Brazilian Environmental Authority.

\begin{tabular}{|c|c|c|c|c|c|c|c|c|}
\hline Parâmetros & $\begin{array}{l}\text { Limites } \\
\text { CONAMA }\end{array}$ & $\begin{array}{c}\text { Águas de } \\
\text { Circulação } \\
\text { Rasa }\end{array}$ & $\%$ & $\begin{array}{l}\text { Águas de } \\
\text { Poços } \\
\text { Profundos }\end{array}$ & $\%$ & $\begin{array}{l}\text { Águas de } \\
\text { Superfície }\end{array}$ & $\%$ & $\begin{array}{c}\text { Total } \\
\%\end{array}$ \\
\hline Al dissolvido & $\begin{array}{c}0,10 \mathrm{mg} \mathrm{L}^{-1}(*) \\
0,20 \mathrm{mg} \mathrm{L}^{-1}(* *)\end{array}$ & 5 & 13,51 & 0 & 0 & 7 & 38,88 & 18,46 \\
\hline As total & $0,01 \mathrm{mg} \mathrm{L}^{-1}(* * *)$ & 2 & 5,40 & 1 & 10 & 0 & 0 & 4,61 \\
\hline Ba total & $0,70 \mathrm{mg} \mathrm{L}^{-1}(* * *)$ & 1 & 2,70 & 0 & 0 & 0 & 0 & 1,54 \\
\hline B total & $0,50 \mathrm{mg} \mathrm{L}^{-1}(* * *)$ & 37 & 100 & 10 & 100 & 19 & 100 & 100 \\
\hline Fe dissolvido & $0,30 \mathrm{mg} \mathrm{L}^{-1} \quad(* * *)$ & 2 & 5,40 & 3 & 30 & 9 & 50 & 21,54 \\
\hline Fluoreto & $\begin{array}{l}1,40 \mathrm{mg} \mathrm{L}^{-1}(*) \\
1,50 \mathrm{mg} \mathrm{L}^{-1}(* *)\end{array}$ & 1 & 2,70 & 0 & 0 & 0 & 0 & 1,54 \\
\hline Mn total & $0,10 \mathrm{mg} \mathrm{L}^{-1} \quad(* * *)$ & 5 & 13,51 & 5 & 50 & 15 & 83,33 & 38,46 \\
\hline Nitrato & $10,00 \mathrm{mg} \mathrm{L}^{-1}(* * *)$ & 9 & 24,32 & 0 & 0 & 0 & 0 & 13,85 \\
\hline Nitrito & $1,00 \mathrm{mg} \mathrm{L}^{-1}(* * *)$ & 1 & 2,70 & 0 & 0 & 0 & 0 & 1,54 \\
\hline $\mathrm{Pb}$ total & $0,01 \mathrm{mg} \mathrm{L}^{-1}(* * *)$ & 2 & 5,40 & 0 & 0 & 1 & 5,55 & 4,61 \\
\hline Sulfato & $250 \mathrm{mg} \mathrm{L}^{-1}(* * *)$ & 0 & 0 & 1 & 10 & 0 & 0 & 1,54 \\
\hline $\begin{array}{l}\text { Sólidos Totais } \\
\text { Dissolvidos }\end{array}$ & $\begin{array}{c}500 \mathrm{mg} \mathrm{L}^{-1}(*) \\
1.000 \mathrm{mg} \mathrm{L}^{-1}(* *)\end{array}$ & 2 & 5,88 & 2 & 25 & 2 & 11,76 & 10,17 \\
\hline $\mathrm{pH}$ & 6,0 a $9,0(*)$ & 9 & 24,32 & 0 & 0 & 1 & 5,55 & 15,38 \\
\hline OD & Não inferior a $5 \mathrm{mg} \mathrm{L}^{-1}(*)$ & 16 & 51,61 & 3 & 30 & 6 & 40 & 44,64 \\
\hline DBO & $\begin{array}{c}5 \text { dias a } 20{ }^{\circ} \mathrm{C} \text { até } 5 \mathrm{mg} \mathrm{L}^{-1} \\
(*)\end{array}$ & 5 & 16,13 & 1 & 10 & 11 & 73,33 & 30,36 \\
\hline $\begin{array}{l}\text { Coliformes } \\
\text { Termotolerantes }\end{array}$ & $\begin{array}{c}1.000 \text { coliformes } \\
\text { termotolerantes por } \\
100 \mathrm{~mL}\left(^{*}\right)\end{array}$ & 26 & 83,87 & 8 & 80 & 0 & 0 & 60,71 \\
\hline
\end{tabular}

Ausência em $100 \mathrm{~mL}(* *)$

(*) Classe 2 do Conama 357/05; (**) Limites para consumo humano, Conama 396/08; (***) Mesmo Valor Máximo Permitido (VMP) para as duas resoluções do Conama e em realce os parâmetros que apresentaram pontos em inconformidade com maior frequência.

Na Figura 2, apresenta-se a distribuição do número de parâmetros fora do permitido pelas legislações de referência, que cada ponto amostrado (poços tubulares e escavados, nascentes e pontos superficiais) apresentou e aponta também a localização das culturas agrícolas de inverno da bacia. Em toda a extensão da BHRSD, nos pontos analisados, algum parâmetro apresentou inconformidade, mas o mapa de superfície mostra quais são os pontos mais críticos. As áreas em amarelo coincidem com os adensamentos urbanos, e as de vermelho são as que possuem pontos de coleta de águas superficiais onde há lançamentos de esgotos. As áreas que apresentaram ao menos três parâmetros em inconformidade com a legislação ajustam-se com os limites das plantações, mostrando, assim, a influência das práticas agrícolas na contaminação dos recursos hídricos. As áreas mais claras são as que apenas um parâmetro não atende às resoluções de referência, e seus contornos regulam com áreas mais preservadas da BHRSD. 


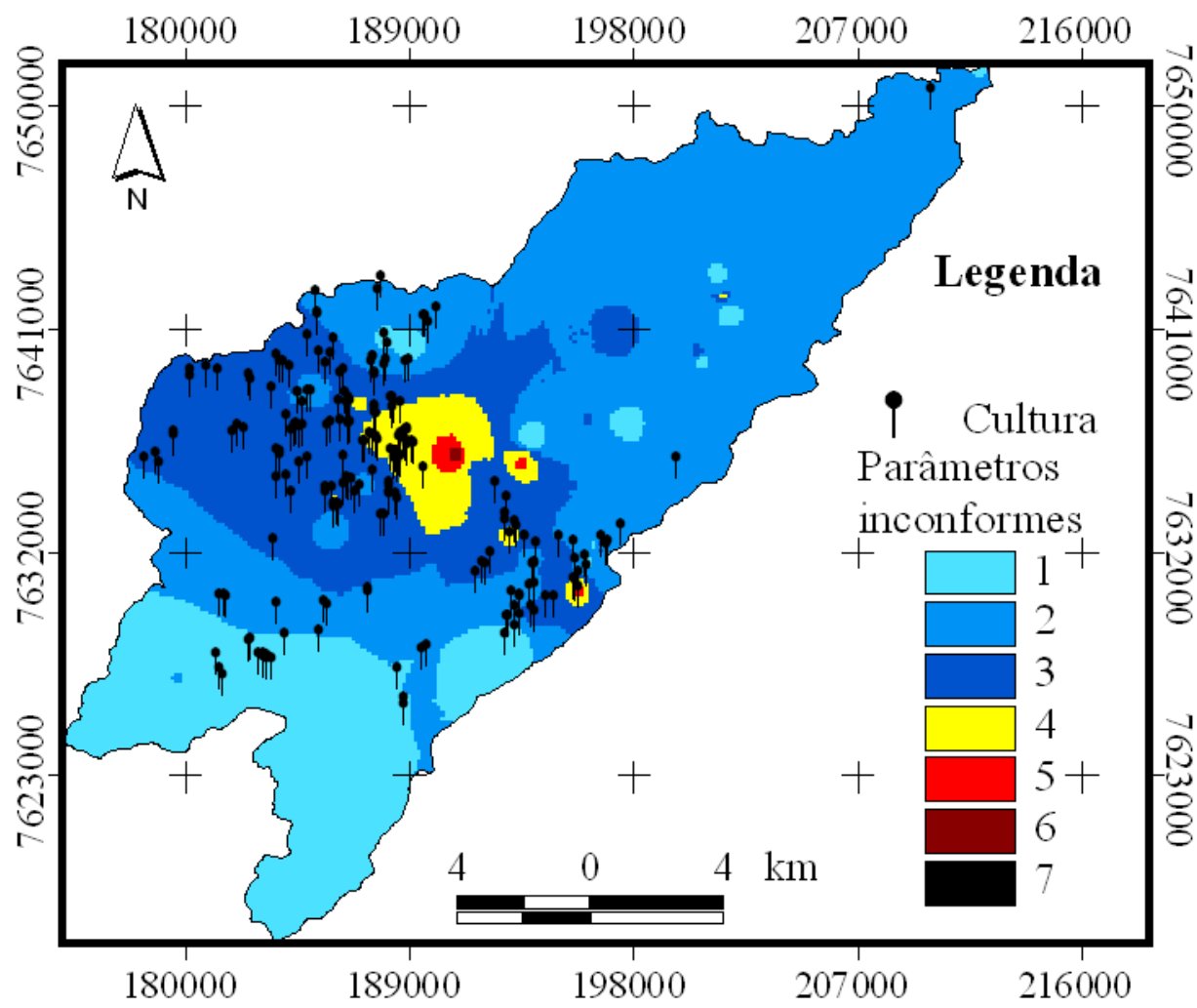

FIGURA 2. Mapa de superfície mostrando a distribuição espacial quanto ao número de parâmetros em inconformidade e a localização das culturas. Surface water map showing spatial distribution of parameters exceeding MCL and location of crops.

A partir das informações extraídas da Tabela 3, do cruzamento com as características geológicas da área e da Figura 2, é possível realizar algumas inferências sobre a origem dessas substâncias.

Quanto ao alumínio dissolvido, a maior parte das amostras apresentou concentração abaixo de $0,1 \mathrm{mg} \mathrm{L}^{-1}$, porém esse parâmetro apresentou teores mais elevados nas águas superficiais $(38,88 \%)$ do que nas águas de circulação profunda. O aumento da concentração de alumínio está, provavelmente, associado com o período das chuvas e, portanto, com a alta turbidez (CETESB, 2005). Eventos de chuva ocorridos durante a campanha de amostragem provocaram claro desvio na distribuição dos resultados desse metal, estabelecendo-se, então, a relação entre os eventos de chuva e a concentração de alumínio. A ocorrência de alumínio pode estar relacionada à presença de minerais alumino-silicatados que estão presentes na BHRSD. O fato de o alumínio não ultrapassar os limites nas águas profundas se deve à facilidade com que é retido pelos processos físico-químicos que ocorrem na zona vadosa.

O boro foi o parâmetro que mais apresentou inconformidade com o valor de referência, visto que $100 \%$ dos pontos amostrados foram superiores ao limite estabelecido. Não se estabeleceu relação com alguma unidade litológica em particular, mas esse elemento pode ocorrer em alguns minerais presentes na área, como biotita e anfibólios (MANSUR et al., 2006). Contudo, a presença do boro nesses minerais não justificaria valores tão altos, e é possível que haja incremento de boro nas águas a partir das atividades antrópicas, já que esse é usado na composição de fertilizantes utilizados na BHRSD, na cultura de tomate. Em pequenas quantidades, o boro é essencial para o bom desenvolvimento das plantas. Os valores extremamente baixos ou elevados de boro levam as folhas a mostrarem manifestações visíveis das características desses extremos (SALVADOR et al., 2003). 
O VMP para o ferro é $0,30 \mathrm{mg} \mathrm{L}^{-1}$, tanto para o CONAMA 357/05 (classe 2) como para o CONAMA 398/06 (consumo humano), e foi nas águas superficiais que os teores de ferro se apresentaram acima do limite estabelecido com maior frequência, (50\%) e, nos poços profundos, $30 \%$ das amostras ultrapassaram o valor de referência. Na bacia, por exemplo, encontram-se minerais ferromagnesianos (piroxênios, hornblendas), entretanto o ferro também pode estar relacionado à ocorrência de ferrobactérias ou mesmo à corrosão do revestimento ou filtro do poço (SANTOS, 2000). Nas águas superficiais, o nível de ferro aumenta nas estações chuvosas devido ao carreamento de solos e à ocorrência de processos de erosão das margens (CETESB, 2005). A relação entre chuva e maior quantidade de ferro nas águas superficiais justificaria esse alto percentual nas amostras, já que a maioria das amostras foi coletada em dias de chuva. Os resíduos agrícolas também são importantes fontes de ferro para as águas da BHRSD, por ser o ferro constituinte de diversos agrotóxicos.

O elemento que depois do boro mais apresentou amostras com valores acima do estabelecido pelas legislações foi o manganês $(38,46 \%)$, principalmente nas águas superficiais e nas águas dos poços profundos. Normalmente, as concentrações desse elemento não ultrapassam $0,2 \mathrm{mg} \mathrm{L}^{-1} \mathrm{em}$ quase todas as águas naturais (SANTOS, 2000), porém 24,62\% das amostras ultrapassaram essa característica. Dentre as muitas fontes do manganês, encontram-se os resíduos de fertilizantes e os fungicidas utilizados na BHRSD; como exemplos, podem ser citados o Mancozeb e o Manzate 800. Dessa forma, pode-se relacionar à agricultura suas grandes concentrações nas águas superficiais da área de estudo. $\mathrm{O}$ alto teor de manganês nas águas profundas pode ter relação com a composição das rochas da região, já que esse é encontrado em minerais existentes na área (granada, biotita e hornblenda servem como exemplo). As águas dos poços podem também estar sendo contaminadas por fontes antrópicas, uma vez que, de forma geral, os poços tubulares na BHRSD são mal revestidos ou sem revestimento algum.

Outro parâmetro que apresentou parte dos valores em inconformidade foi o nitrato; (cerca de $24 \%$ nas águas de circulação rasa (incluem poços escavados e nascentes). De acordo com MUELLER \& HELSEL (2001) e SINGH et al. (2005), o nitrato na água subterrânea acima de cerca de $5 \mathrm{mg} \mathrm{L}^{-1}$ indica a ocorrência de alguma fonte antrópica, podendo estar relacionada às fontes pontuais (esgotos) ou difusas (resíduos da agricultura).

Algumas amostras de águas de circulação rasa $(24,32 \%)$ apresentaram pH em inconformidade com a legislação de referência (CONAMA 357/05). A média do pH das amostras é 6,62, valor mínimo 5,84 e máximo 8,24. Como o limite da legislação é entre 6 e 9, as amostras que estão em desacordo apresentam $\mathrm{pH}$ abaixo desse limite.

O oxigênio dissolvido está abaixo do limite mínimo da norma do CONAMA 357/05 em 40\% dos pontos superficiais, sendo $51,61 \%$ dos pontos do aquífero raso e em $30 \%$ dos poços profundos. Embora não seja um parâmetro tão significativo em água subterrânea, o oxigênio dissolvido é importante para as águas superficiais, já que, quando é encontrado em concentrações baixas, geralmente está relacionado a processos intensos de eutrofização, com possibilidade de ocorrência de mortandade de peixes e outros seres vivos do meio aquático (PIVELI \& KATO, 2005).

Quanto aos valores de demanda bioquímica de oxigênio (DBO), as águas superficiais são as que apresentam maior percentual (73,33\%) acima do limite do CONAMA 357/05; em seguida, as águas do aquífero raso $(16,13 \%)$, e por último as dos poços profundos com 10\%. O resultado foi, portanto, conforme o esperado; as amostras que mais excederam os limites foram as provenientes dos rios, lagos e barragens por estarem mais expostas ao aporte de matéria orgânica e consequente diminuição do oxigênio, já que esse é consumido pelas bactérias no processo de obtenção de energia (SANTOS, 2000).

O parâmetro coliformes termotolerantes ultrapassou o limite do CONAMA 396/08 (consumo humano) em todas as amostras subterrâneas, que são utilizadas por mais da metade da população de São José de Ubá - RJ para consumo humano. Pelo fato de as águas superficiais não serem empregadas no consumo humano, o VMP é bem menos restritivo e por isso essas águas não se 
apresentam acima do limite, entretanto também foram detectados nessas amostras coliformes termotolerantes.

As resoluções CONAMA 357/05 e 396/08 estabelecem valores máximos permitidos distintos para os diversos agrotóxicos, e em alguns casos, o limite para consumo humano (CONAMA 396/08) é menos restritivo que para água utilizada para irrigar hortaliças consumidas cruas (CONAMA 357/05). Na Tabela 4, apresentam-se os resultados das análises dos compostos organoclorados e organofosforados.

TABELA 4. Resultados dos compostos organoclorados e organofosforados analisados. Results of the analyzed organochlorides and organophosphorus compounds.

\begin{tabular}{|c|c|c|c|c|c|c|c|c|c|c|c|c|c|c|}
\hline & & & & & & & & & ID & & & & & \\
\hline Par. & Compostos & Amostra & $7 \mathrm{~N}$ & $14 \mathrm{R}$ & $53 \mathrm{R}$ & $4 \mathrm{P}$ & $7 \mathrm{P}$ & $8 \mathrm{P}$ & $12 \mathrm{P}$ & $24 \mathrm{~S}$ & $29 \mathrm{~S}$ & $32 \mathrm{~S}$ & $36 \mathrm{~S}$ & $37 \mathrm{~S}$ \\
\hline \multirow{18}{*}{ 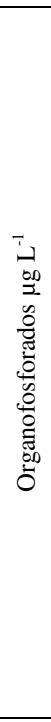 } & \multirow{2}{*}{$\begin{array}{l}\text { Clorpirofós } \\
\text { (SPE) } \\
30 \mu \mathrm{g} \mathrm{L}^{-1 *}\end{array}$} & 1 & ND & ND & LOD $<y<L O Q$ & $\mathrm{ND}$ & ND & $\mathrm{ND}$ & $\mathrm{ND}$ & ND & ND & $\mathrm{ND}$ & ND & ND \\
\hline & & 2 & ND & ND & ND & $\mathrm{ND}$ & ND & $\mathrm{ND}$ & ND & $\mathrm{ND}$ & $\mathrm{ND}$ & ND & $\mathrm{LOD}<\mathrm{y}<\mathrm{LOQ}$ & ND \\
\hline & \multirow{2}{*}{$\begin{array}{l}\text { Clorpirofós } \\
\text { (ELL) } \\
30 \mu \mathrm{g} \mathrm{L}^{-1^{*}}\end{array}$} & 1 & ND & ND & ND & ND & ND & ND & ND & 0,128 & ND & ND & ND & 0,252 \\
\hline & & 2 & ND & ND & ND & ND & ND & ND & $\mathrm{ND}$ & 0,151 & ND & ND & ND & 0,042 \\
\hline & \multirow{2}{*}{ Diazinon (ELL) } & 1 & ND & ND & $\mathrm{ND}$ & ND & $\mathrm{ND}$ & ND & ND & 0,031 & ND & ND & $\mathrm{ND}$ & 0,223 \\
\hline & & 2 & ND & ND & ND & ND & ND & ND & $\mathrm{ND}$ & ND & ND & ND & $\mathrm{ND}$ & ND \\
\hline & \multirow{2}{*}{ Diclorvós (SPE) } & 1 & ND & ND & ND & ND & ND & ND & ND & ND & $\mathrm{ND}$ & ND & ND & ND \\
\hline & & 2 & ND & ND & ND & ND & ND & ND & $\mathrm{ND}$ & ND & $\mathrm{ND}$ & ND & 0,067 & ND \\
\hline & \multirow{2}{*}{$\begin{array}{c}\text { Fenitrotion } \\
\text { (ELL) }\end{array}$} & 1 & ND & $\mathrm{ND}$ & ND & ND & ND & $\mathrm{ND}$ & ND & $<\mathrm{LOQ}$ & $\mathrm{ND}$ & $\mathrm{ND}$ & ND & 0,09 \\
\hline & & 2 & ND & ND & ND & ND & ND & ND & $\mathrm{ND}$ & $\mathrm{ND}$ & ND & ND & $\mathrm{ND}$ & ND \\
\hline & \multirow{2}{*}{ Fentoato (ELL) } & 1 & ND & ND & ND & ND & ND & ND & $\mathrm{ND}$ & 0,047 & ND & ND & $\mathrm{ND}$ & 0,293 \\
\hline & & 2 & ND & ND & ND & ND & ND & ND & $\mathrm{ND}$ & ND & ND & ND & ND & ND \\
\hline & \multirow{2}{*}{$\begin{array}{c}\text { Malation (ELL) } \\
190 \mu \mathrm{g} \mathrm{L} \mathrm{L}^{-1 *} \\
0,1 \mu \mathrm{g} \mathrm{L}^{-1 * *}\end{array}$} & 1 & ND & ND & ND & ND & ND & ND & ND & $<\mathrm{LOQ}$ & ND & ND & ND & 0,05 \\
\hline & & 2 & ND & ND & ND & ND & ND & ND & ND & ND & ND & ND & ND & ND \\
\hline & \multirow{2}{*}{$\begin{array}{l}\text { Metil-paration } \\
\text { (SPE) } \\
0,04 \mu \mathrm{g} \mathrm{L}^{-1 * *}\end{array}$} & 1 & ND & $\mathrm{ND}$ & ND & ND & ND & $\mathrm{ND}$ & ND & ND & $\mathrm{ND}$ & ND & ND & ND \\
\hline & & 2 & ND & ND & 0,667 & ND & ND & ND & ND & ND & ND & ND & ND & ND \\
\hline & Metil-paration & 1 & ND & ND & ND & $\mathrm{ND}$ & ND & $\mathrm{ND}$ & ND & $\mathrm{ND}$ & ND & ND & ND & 0,11 \\
\hline & $\begin{array}{c}(\text { ELL) } \\
0,04 \mu \mathrm{g} \mathrm{L}^{-1 * *}\end{array}$ & 2 & ND & ND & ND & ND & ND & ND & ND & $<\mathrm{LOQ}$ & ND & ND & ND & ND \\
\hline \multirow{10}{*}{ 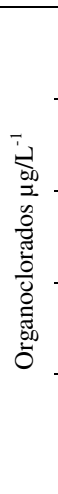 } & Aldrin (SPE) & 1 & ND & ND & $\mathrm{LOD}<\mathrm{y}<\mathrm{LOQ}$ & ND & ND & ND & ND & ND & ND & ND & ND & ND \\
\hline & $\begin{array}{c}0,03 \mu \mathrm{g} \mathrm{L}^{-1^{*}} \\
0,005 \mu \mathrm{g} \mathrm{L}^{-1 * *}\end{array}$ & 2 & ND & ND & ND & ND & ND & ND & $\mathrm{ND}$ & ND & ND & ND & $\mathrm{LOD}<\mathrm{y}<\mathrm{LOQ}$ & ND \\
\hline & Lindano (SPE) & 1 & 0,03 & 0,014 & 0,043 & 0,024 & 0,046 & 0,016 & 0,024 & ND & $\mathrm{ND}$ & ND & 0,028 & ND \\
\hline & $\begin{array}{c}2 \mu \mathrm{g} \mathrm{L}^{-1^{*}} \\
0,02 \mu \mathrm{g} \mathrm{L}^{-1 * *}\end{array}$ & 2 & ND & 0,023 & ND & 0,023 & 0,012 & 0,015 & 0,018 & 0,042 & 0,019 & ND & 0,034 & ND \\
\hline & \multirow{2}{*}{$\begin{array}{c}\text { Lindano (ELL) } \\
2 \mu \mathrm{g} \mathrm{L}^{-1 *} \\
0,02 \mu \mathrm{g} \mathrm{L}^{-1^{* * *}}\end{array}$} & 1 & ND & ND & ND & ND & ND & $\mathrm{ND}$ & ND & 0,093 & ND & ND & ND & 0,087 \\
\hline & & 2 & ND & ND & ND & ND & ND & ND & ND & 0,085 & ND & ND & ND & 0,079 \\
\hline & \multirow{2}{*}{$\begin{array}{l}\text { Metolcloro } \\
\text { (SPE) } \\
10 \mu \mathrm{g} \mathrm{L}^{-1^{* * *}}\end{array}$} & 1 & ND & ND & ND & ND & ND & $\mathrm{ND}$ & ND & ND & 0,393 & ND & ND & $\mathrm{ND}$ \\
\hline & & 2 & ND & ND & ND & ND & ND & $\mathrm{ND}$ & ND & ND & 0,361 & ND & ND & ND \\
\hline & \multirow{2}{*}{$\begin{array}{c}\text { Endossulfan } \\
(\alpha+\beta)(\mathrm{SPE}) \\
20 \mu \mathrm{g} \mathrm{L}^{-1 *} \\
0,056 \mu \mathrm{g} \mathrm{L}^{-1^{-* *}}\end{array}$} & 1 & ND & ND & ND & ND & $\mathrm{LOD}<\mathrm{y}<\mathrm{LOQ}$ & $\mathrm{ND}$ & 0,102 & ND & ND & 0,011 & 0,06 & ND \\
\hline & & 2 & ND & ND & ND & ND & ND & ND & ND & ND & ND & $\mathrm{LOD}<\mathrm{y}<\mathrm{LOQ}$ & ND & ND \\
\hline
\end{tabular}

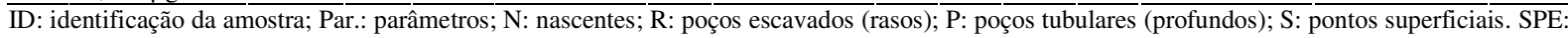
extração em fase sólida; ELL: extração líquido-líquido; ND: não detectado; LOD: limite de detecção; LOQ: limite de quantificação; y: concentração obtida do agrotóxico; (*) limites para consumo humano, CONAMA 396/08; (**) Classe 2 do CONAMA 357/05; (***) mesmo valor máximo permitido (VMP) para as duas resoluções do CONAMA

Dos agrotóxicos organofosforados analisados, somente o Malation e o Clorpirofós são mencionados pela Resolução 396/08, e apenas o Malation e o Paration são citados na Resolução 357/05. Nenhum dos 12 pontos ultrapassou os limites definidos pelas resoluções, porém, em algumas amostras, os agrotóxicos analisados (Clorpirofós, Diclorvós, Diazinon, Fentoato, Fenitrotion, Malation e Metil-paration) foram identificados. As amostras que acusaram organofosforados foram coletadas em período chuvoso, aumentando, portanto, a possibilidade de solubilização dos pesticidas pela chuva. São amostras representantes de águas superficiais. A única amostra de poço (escavado) que acusou a presença de organofosforados não confirmou essa presença na duplicata. Embora menos persistentes que os organoclorados, os organofosforados possuem toxidade elevada. 
Os organoclorados são compostos de alta persistência e toxicidade (ARRUDA \& JARDIM, 2007) e encontram-se presentes em quase todo ambiente e armazenam-se em plantas e em tecidos animais. As restrições a sua utilização originam-se da grande capacidade residual dos mesmos e da possível ação carcinogênica. Em relação aos resultados das análises dos pesticidas organoclorados, foram avaliados 12 pontos com amostras em duplicata, e desses, sete apresentaram suspeitas de contaminação por Lindano e/ou $\alpha$-Endossulfan, já que esses analitos se encontram acima dos valores máximos permitidos pelo CONAMA 357/05.

\section{CONCLUSÕES}

O mapeamento da qualidade dos recursos hídricos da BHRSD auxiliou na identificação das áreas mais vulneráveis e facilitou a averiguação sobre a origem da contaminação das águas da bacia.

As águas da BHRSD apresentaram certo grau de comprometimento em relação a sua qualidade, já que diversas amostras se apresentaram em desacordo com os limites estabelecidos pela legislação brasileira, Resolução CONAMA 357/05 (classe 2), para as águas superficiais, e CONAMA 396/08 (limites para consumo humano), para as águas subterrâneas. As causas podem ser tanto naturais como antrópicas.

Os parâmetros $\mathrm{Al}$ e Fe podem estar relacionados à geologia da área, no entanto o Fe também pode estar relacionado à ocorrência de ferrobactérias ou mesmo à corrosão do revestimento ou filtro do poço; já os valores dos parâmetros OD, DBO, nitrato e coliformes termotolerantes, aparentemente, são reflexos do uso e da ocupação do solo na BHRSD, dos intensos processos de eutrofização que as águas da bacia vêm sofrendo, não só com lançamentos dos resíduos agrícolas, mas também com esgotos e criação de animais.

$\mathrm{O}$ excesso de boro, manganês, Lindano e $\alpha$-Endossulfan está provavelmente relacionado diretamente com as atividades agrícolas.

\section{REFERÊNCIAS}

ABREU, B.M.; FIDALGO, E.C.C Mapeamento do uso e ocupação da terra na Bacia Hidrográfica do Rio São Domingos. In: WORKSHOP DE INTEGRAÇÃO DE INFORMAÇÕES OBTIDAS NO ÂMBITO DO PROJETO PRODETAB AQUÍFEROS, 1., 2006, Rio de Janeiro. Anais ... Rio de Janeiro: Embrapa, 2006. 1 CD-ROM.

ANDRADE, E.M. de; ARAÚJO, L. de F.P.; ROSA, M.F.; DISNEY, W.; ALVES, A.B. Seleção dos indicadores da qualidade das águas superficiais pelo emprego da análise multivariada. Engenharia Agrícola, Jaboticabal, v.27, n.3, p.683-690, set./dez. 2007. Disponível em:

$<$ http://www.scielo.br/scielo.php?script=sci_arttext\&pid=S0100>. Acesso em: 5 mar. 2008.

APHA. AMERICAN PUBLIC HEALTH ASSOCIATION. Standard methods for the examination of water and wastewater. $20^{\text {th }}$ ed. Washington, 1998. $1.220 \mathrm{p}$.

ARRUDA, T.L. de; JARDIM, W.F. Tratamento de água subterrânea contaminada com compostos organoclorados usando ferro elementar e o reagente de Fenton. Química Nova, São Paulo, v.30, n.7, p.1.628-1.632, 2007.

ÁVILA, C.J.C.P.; ASSAD, E.D.; VERDESIO, J.J.; E.I.D, N.J.; SOARES, W.; FREITAS, M.A.V. DE. Geoprocessamento da informação hidrológica. ASFAGRO: trabalhos técnicos 2007.

Disponível em: <http://www.asfagro.org.br/trabalhos_tecnicos>. Acesso em: 4 jun. 2007.

BRASIL. Conselho Nacional do Meio Ambiente. Resolução $n^{\circ} 35723$ de Janeiro 2005. Disponível em: <www.mma.gov.br/port/conama>. Acesso em: 3 jul. 2005.

BRASIL. Conselho Nacional do Meio Ambiente. Resolução n 3963 de Abril 2008. Disponível em: <www.mma.gov.br/port/conama>. Acesso em: $1^{\circ}$ jun. 2008. 
CETESB. COMPANHIA DE TECNOLOGIA DE SANEAMENTO AMBIENTAL. Parâmetros de qualidade. 2005. Disponível em <http://www.cetesb.sp.gov.br/agua/rios/parametros.htm>. Acesso em: 5 ago. 2005.

DONADIO, N.M.M.; GALBIATTI, J.A.; PAULA, R.C. DE. Qualidade da água de nascentes com diferentes usos do solo na bacia hidrográfica do Córrego Rico, São Paulo, Brasil. Engenharia Agrícola, Jaboticabal, v.25, n.1, p.115-125, 2005.

FERREIRA, C.R.C.; LA TERRA, E.F.; MENEZES, P.T.L. Modelagem geofísica para água subterrânea em aquíferos fissurais em São José de Ubá-RJ. In: WORKSHOP DE INTEGRAÇÃO DE INFORMAÇÕES OBTIDAS NO ÂMBITO DO PROJETO PRODETAB AQUÍFEROS, 1. ., 2006, Rio de Janeiro. Anais ... Rio de Janeiro: Embrapa, 2006. 1 CD-ROM.

FREITAS, P.L. de; MANZATO, C.V.; COUTINHO, H.L. da C. A crise de energia e a degradação dos recursos naturais - solo, ar, água e biodiversidade. Boletim Informativo, Viçosa - MG, v.26, n.4, p.7-9, 2001.

IBGE. INSTITUTO BRASILEIRO DE GEOGRAFIA E ESTATÍSTICA. Censo 2000. Disponível em: <http://www.ibge.gov.br/censo/>. Acesso em: 18 jun. 2007.

LUMBRERAS, J.F.; NAIME, U.J.; MOTTA, P.E.F.; PALMIERI, F.; CARVALHO FILHO, A. de; BARUQUI, A.M.; CALDERANO, S.B.; FIDALGO, E.C.C.; MOREIRA, D.M. de. Solos da Bacia Hidrográfica do Rio São Domingos. In: WORKSHOP DE INTEGRAÇÃO DE INFORMAÇÕES OBTIDAS NO ÂMBITO DO PROJETO PRODETAB AQUÍFEROS, 1., 2006, Rio de Janeiro. Anais ... Rio de Janeiro: Embrapa, 2006. 1 CD-ROM.

MANSUR, K.L.; MEDEIROS, F.; VIEIRA H.; MARTINS, A.M.; PRADO, R.B.; MENEZES, J.M.; SILVA, G.C.J. Avaliação preliminar: geologia e alguns parâmetros da qualidade da água subterrânea nas microbacias de Santa. Maria/Cambiocó e Barro Branco. In: WORKSHOP DE INTEGRAÇÃO DE INFORMAÇÕES OBTIDAS NO ÂMBITO DO PROJETO PRODETAB AQUÍFEROS, 1., 2006, Rio de Janeiro. Anais ... Rio de Janeiro: Embrapa, 2006. 1 CD-ROM.

MENEZES, J.M.; SILVA Junior., G.C. da; SANTOS, R.T. dos. Hidrogeoquímica de aquíferos fraturados: estudo de caso na bacia hidrográfica do Rio São Domingos, noroeste do Estado do Rio de Janeiro. Revista Águas Subterrâneas, São Paulo, v.21, n.1, p.10-16, 2007.

MUELLER, D.K.; HELSEL D.R. Nutrients in the nation's waters - too much of a good thing. Washington: Geological Survey, 2001. 24 p. (Circular, 1136)

PAUWELS, H.; LACHASSAGNE, P.C.; BORDENAVE, P.; FOUCHER, J.; MARTELAT, A. Temporal variability of nitrate concentration in a schist aquifer and transfer to surface waters. Applied Geochemistry, Amsterdam, v.16, n.6, p.583-596, 2001.

PIVELI, R.P.; KATO, M.T. Qualidade das águas e poluição: aspectos físico-químicos. São Paulo: Associação Brasileira de Engenharia Sanitária e Ambiental, 2005. 285 p.

PRADO, R.B.; MENEZES, J.M.; MANSUR, K.L.; MARTINS, A.M.; FREITAS, P.L.; SILVA JÚNIOR, G.C.; PIMENTA, T.S.; LIMA, A.L. Parâmetros de qualidade da água e sua relação espacial com as fontes de contaminação antrópicas e naturais: bacia hidrográfica do Rio São Domingos - São José de Ubá - RJ. In: SIMPÓSIO BRASILEIRO DE RECURSOS HÍDRICOS, 16., 2005. Anais... João Pessoa: ABRH, 2005. 1 CD-ROM.

RAO, S.N. Groundwater potential index in a crystalline terrain using remote sensing data. Environmental Geology, Berlin, v.50, n.7, p.1.067-1.076, 2006.

ROMERO, A.H.H.; HERNÁNDEZ, C.T.; MALO, E.A.; MENDOZA, R.B. Water quality and presence of pesticides - southern México. Marine Pollution Bulletin, Oxford, v.48, n.11-12, p.1.130-1.141, 2004. 
SALVADOR, J.O.; MOREIRA, A.; VOLTA, E.M.; CABRAL, C.P. Influência do boro e do manganês no crescimento e na composição mineral de mudas de goiabeira. Ciência e Agrotecnologia, Lavras, v.27, n.2, p.325-331, 2003.

SANTOS, A.C. Noções de hidroquímica. In: FEITOSA, F.A.C.; MANOEL FILHO, J. Hidrogeologia: conceitos e aplicações. Fortaleza: CPRM, 2000. p.81-102.

SINGH, K.P.; SINGH, V.K.; MALLIK, A.; BASANT, N. Distribution of nitrogen species in groundwater aquifers of an industrial area. Environment Geochemistry and Health, Amsterdam, v.28, n.5, p.473-485, 2005.

STIGTER, T.Y.; RIBEIRO, L.; CARVALHO DILL, A.M.M. Application of a groundwater quality index. Journal of Hydrology, Amsterdam, v.327, n.3-4, p.578-591, 2006.

ZHOU, R.; ZHU, L.; KONG, Q. Persistent chlorinated pesticides in fish species from Qiantang River in East China. Chemosphere, Amsterdam, v.68, n.5, p.838-847, 2007. 